\title{
How Safe and Effective Is Shifting from Pterional to Supraorbital Keyhole Approach for Clipping Ruptured Anterior Circulation Aneurysms? A Surgeon's Transition Phase Comparative Study
}

\author{
Sivashanmugam Dhandapani ${ }^{1, \odot}$ Rajasekhar Narayanan ${ }^{1}$ Manju Dhandapani², Hemant Bhagat $^{3}$
}

1Department of Neurosurgery, Postgraduate Institute of Medical Education and Research (PGIMER), Chandigarh, India

${ }^{2}$ National Institute of Nursing Education (NINE), Postgraduate Institute of Medical Education and Research (PGIMER), Chandigarh, India

${ }^{3}$ Department of Neuroanesthesia, Postgraduate Institute of Medical Education and Research (PGIMER), Chandigarh, India
Address for correspondence Sivashanmugam Dhandapani, MCh, Department of Neurosurgery, Postgraduate Institute of Medical Education and Research (PGIMER), Sector 12, Chandigarh 160012, India (e-mail: ssdhandapani.neurosurg@gmail.com).

J Neurosci Rural Pract 2021;12:512-517.

\begin{abstract}
Keywords

- aneurysm

- ruptured

- keyhole

- pterional

- intraoperative rupture

$-\mathrm{DCl}$

- outcome

Background Comparative studies between standard pterional and supraorbital keyhole approaches for aneurysms had potential biases with the heterogeneity of patient selection, differences among surgeons, or varying expertise across the surgeon's learning curve. This is a study of a surgeon's transition from pterional to keyhole approach for early clipping of selected consecutive ruptured anterior circulation aneurysms.

Methods Patients more than 18 years, presenting within 72 hours of ictus, in good clinical grades 1 to 3, no midline shift, with saccular aneurysms less than $25 \mathrm{~mm}$ at either communicating segment of internal carotid artery, anterior communicating artery, or middle cerebral artery segment till bifurcation were studied between the last 25 cases of pterional and first 25 cases of the keyhole, for the intraoperative and postoperative surgical outcome parameters.

Results There was no significant difference among baseline parameters, including the location of aneurysms across both groups. While only four cases of pterional had an intraoperative ventricular puncture, the lumbar drain was electively inserted in all keyhole patients. The intraoperative parameters, such as a dural tear, adequate parent vessel exposure, temporary clipping, and intraoperative rupture, did not show any significant difference. None had immediate postoperative deficits. While delayed cerebral ischemia and wound complaints were similar in both groups, temporal hollowing and chewing difficulty were significantly more in pterional patients $(p=0.01)$.

Conclusion A surgeon experienced in pterional approach can comfortably and safely shift to the keyhole for early clipping of selected ruptured aneurysms less than $25 \mathrm{~mm}$, with a comparable surgical outcome but better cosmesis and mastication.
\end{abstract}

published online June 10, 2021
DOI https://doi.org/

10.1055/s-0041-1727301

ISSN 0976-3147 (c) 2021. Association for Helping Neurosurgical Sick People.

This is an open access article published by Thieme under the terms of the Creative Commons Attribution-NonDerivative-NonCommercial-License, permitting copying and reproduction so long as the original work is given appropriate credit. Contents may not be used for commercial purposes, or adapted, remixed, transformed or built upon. (https://creativecommons.org/licenses/by-nc-nd/4.0/).

Thieme Medical and Scientific Publishers Pvt. Ltd. A-12, 2nd Floor, Sector 2, Noida-201301 UP, India 


\section{Introduction}

Subarachnoid hemorrhage (SAH) has an enormous burden of morbidity, more so in low- and middle-income countries. ${ }^{1-4}$ The role of the supraorbital keyhole approach for intracranial aneurysms, despite being a matter of debate, has relevance in countries where widespread use of endovascular coiling is still not economically viable.

The standard pterional craniotomy has stood the test of time with feasibility to do ventricular puncture, more extensive Sylvian fissure dissection, even in the relatively tense brain, drilling of anterior clinoid process, ability to tackle multiple, giant and complex aneurysms, and spacious enough to manage inadvertent complications. However, this requires a long skin incision, extensive dissection, and has the risk for adverse effects inherent to the broad exposure. As a result, the supraorbital keyhole approach is gaining grounds since van Lindert et al reported their technique in 1998 as a minimally invasive approach for aneurysmal clipping in parallel with the evolution of endovascular techniques. ${ }^{5}$

Although retrospective descriptive studies of minimally invasive approaches are ample in the literature, there is a paucity of controlled studies comparing standard pterional and supraorbital keyhole approaches for ruptured intracranial aneurysms. Heterogeneity of patient selection, differences among surgeons, and varying expertise across a surgeon's learning curve are some of the major lacunae of bias in these. This is a single-surgeon transition-phase comparative study on early clipping of select consecutive anterior circulation aneurysms presenting with $\mathrm{SAH}$, between the last 25 cases of pterional craniotomy and first 25 cases of supraorbital keyhole approach.

\section{Methods}

The first 25 consecutive patients of SAH who underwent supraorbital keyhole clipping by a single surgeon with the following criteria were enrolled. The selection criteria included age more than 18 years, presentation within 72 hours of ictus, the World Federation of Neurosurgical Societies (WFNS) grades 1 to 3 , computed tomography (CT) showing no midline shift ( $\geq 5 \mathrm{~mm}$ ), CT Angiography revealing saccular aneurysms less than $25 \mathrm{~mm}$ at either communicating segment of internal carotid artery (commICA), anterior communicating (Acom) artery, or middle cerebral artery (MCA) segment till bifurcation. The last 25 consecutive cases of pterional clipping by the same surgeon with identical selection criteria were included as historical controls.

\section{Surgical Techniques}

Clipping was performed in all these cases within 24 hours of admission. The side of the surgical approach was determined as per the location and predisposition of the aneurysm. Pterional craniotomy utilized a curvilinear incision extending from just above the zygomatic arch extending an inch behind the hairline to just across the midline. Free bone flap craniotomy fashioned using the drill, followed by durotomy. The ventricular puncture was performed in the case of the tense brain with hydrocephalus. Sylvian fissure dissection was done, the carotid and other cisterns were defined, and the proximal vessels were identified. Temporary clipping was done, followed by neck dissection and permanent clipping. The aneurysm was punctured. Intraoperatively, indocyanine green was used to verify the nonfilling of the aneurysm whenever needed. Other coexisting aneurysms in the same corridor were also clipped. After hemostasis, the wound was closed in layers after the replacement of the bone flap.

In the supraorbital keyhole approach (-Fig. 1), a lumbar drain was inserted preoperatively and kept closed till the durotomy. After an eyebrow incision, keyhole basal craniotomy was done with or without lateral wing sphenoidotomy. The U-shaped dural opening was performed. The lumbar drain was opened intermittently from this time onward to release cerebrospinal fluid (CSF) till the brain was lax. Sylvian fissure was opened along the base as per the necessity. The rest of the dissection and clipping were as mentioned above, with greater use of coaxial clip applicators. Dural closure was followed by replacement and fixing of the bone flap with mini plates and screws. Layered closure was then performed, and the lumbar drain was removed.

Details of aneurysms (-Figs. 2 and 3), intraoperative events such as a dural tear, perioperative CSF drainage, difficult Sylvian fissure with a pial breach, parent vessel exposure, temporary clipping, and intraoperative rupture were noted in both the groups. Patients were managed in the intensive care unit in the immediate postoperative period on oral mimodipine. Neurological monitoring and CT as per the clinical situation were performed. Delayed cerebral ischemia (DCI) was considered based on "occurrence of focal neurological impairment (such as hemiparesis, aphasia, apraxia, hemianopia, or neglect), or a decrease of at least 2 points on the Glasgow coma scale, which was not apparent immediately after clipping, and cannot be attributed to other causes." ${ }^{6}$ Induced hypertension and other measures were used on patients with DCI and their response noted. Patients who worsened despite induced hypertension were termed as irreversible DCI and managed as per the situation. Local wound complaints were also noted down. Patients were discharged after 7 days of ictus and followed-up subsequently. Temporal hollowing, chewing difficulty and cosmesis (-Fig. 4) were assessed at around 3 months, along with repeat angiography to look for the residual aneurysm. Magnetic resonance imaging was also performed at 3 months in patients who underwent keyhole clipping to look for retraction changes.

The two groups were compared for statistically significant differences using SPSS 21 (IBM Corporation, Armonk, New York, United States) utilizing the Chi-square test. Two-sided significance tests were used throughout, and the significance level was kept at $p<0.05$.

\section{Results}

Among 50 patients together, 66\% had aneurysms located in the Acom or MCA, while $14 \%$ had aneurysms at multiple locations (-Table 1). There was no significant difference among 

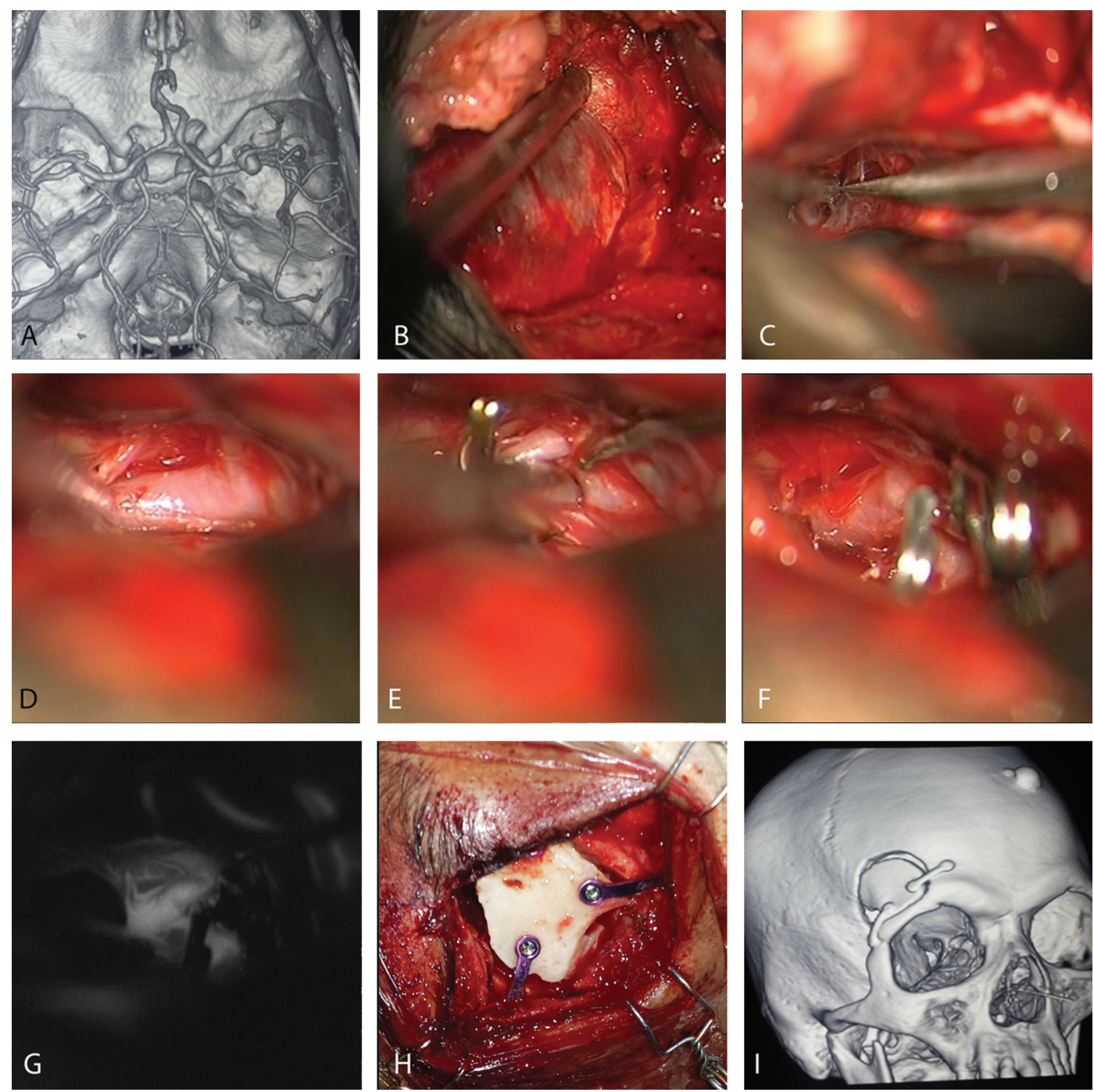

Fig. 1 Illustrative case of keyhole clipping. (A) Computed tomography angiography revealing Rt. Middle cerebral artery aneurysm. (B) Keyhole craniotomy and sphenoidotomy. (C) Sharp dissection of Sylvian fissure, followed by exposure of parent vessel (D) and elective temporary clipping (E). The aneurysms neck is then dissected, and permanent clips applied (F). Indocyanine green intraoperative angiography (G) is routinely used to evaluate the aneurysm and vessel patency. (H and I) Bony closure with mini plates and screws.

baseline parameters, including the location of aneurysms across both groups.

The comparison of intraoperative events between the two groups is shown in $\mathbf{- T a b l e} \mathbf{1}$. While only four cases of pterional approach had an intraoperative ventricular puncture (one failed), the lumbar drain was electively inserted in all the first 25 cases of keyhole approach (three did not drain). All other parameters did not show any significant difference. Dural tear occurred during the craniotomy in four patients of the pterional group, and two of the keyhole group, managed with either direct suturing or duraplasty. Difficult Sylvian fissure dissection was encountered among three in the pterional group and four in the keyhole group. All patients could undergo adequate parent vessel exposure. While temporary clipping was utilized in 20 out of 25 in the pterional craniotomy, all keyhole patients underwent elective temporary clipping. Intraoperative aneurysm rupture occurred in six and seven in pterional and keyhole groups, respectively.
There were no immediate postoperative deficits in either group. DCI was seen overall in $24 \%$ of patients in the pterional group and $16 \%$ in the keyhole group, with no significant difference. While four and three in pterional and keyhole groups had responded to induced hypertension and other measures, irreversible $\mathrm{DCl}$ occurred in $8 \%$ of patients in the pterional group compared with $4 \%$ in the keyhole group. Among the pterional patients, $8 \%$ had some wound-related complaints (one had an infection and one had swelling), none in the keyhole group had any wound issues but not having statistical significance. Some hollowing in the temporal region was noted in 36\% among the pterional patients, and only $4 \%$ among the supraorbital keyhole group $(p=0.01)$. Moderate-to-severe hollowing was noted in $12 \%$ of the pterional group and none in the keyhole group. Difficulty in chewing was complained by $28 \%$ of patients in the pterional craniotomy arm, whereas none of the patients in the keyhole arm had this complaint $(p=0.01)$. No residual aneurysm was present in repeat angiography in any of 

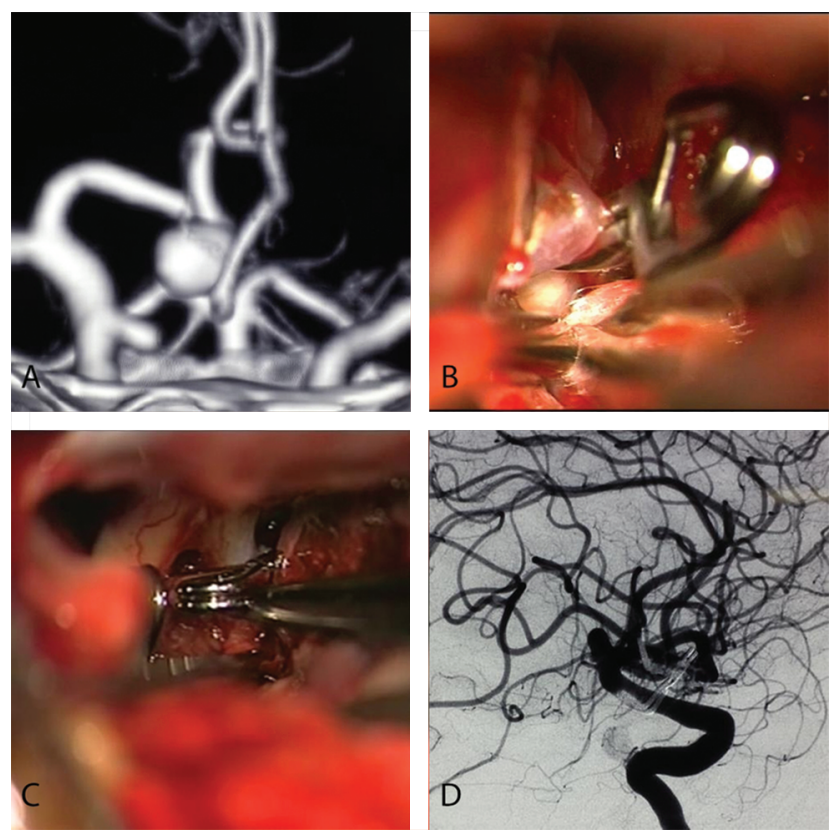

Fig. 2 Keyhole clipping in a patient with double aneurysms. (A) A large anterior communicating artery aneurysm pointing to the right side, with right internal carotid artery communicating segment aneurysm. (B) Postclipping status of Acom complex, and (C) shows right angled fenestrated clip encircling commICA. (D) Postoperative angiography confirmation of complete clipping. Acom, anterior communicating; commICA, communicating segment of internal carotid artery.
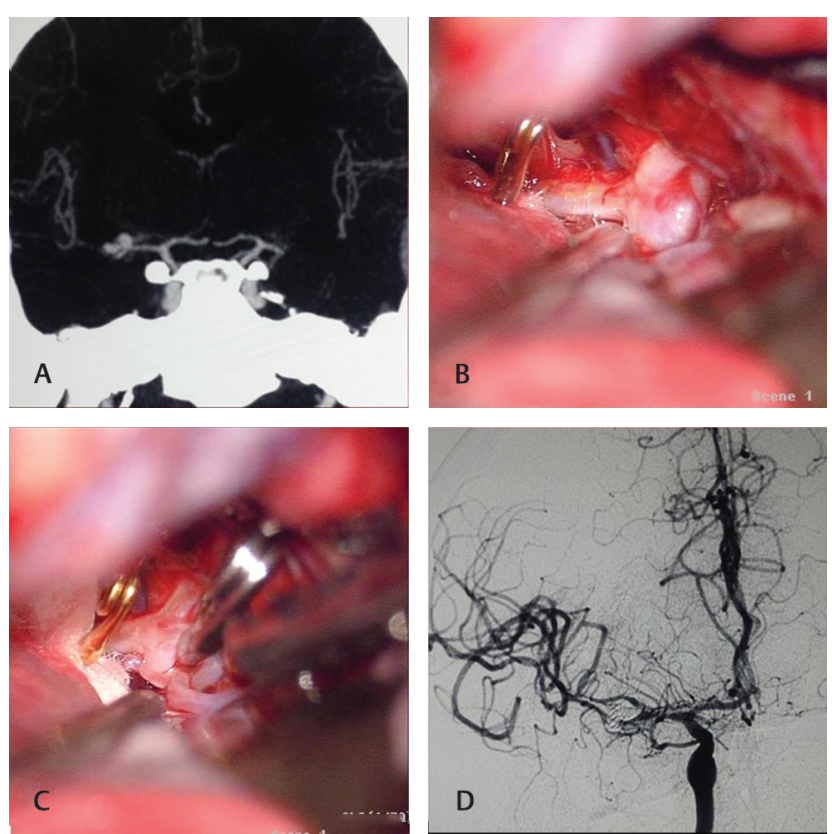

Fig. 3 Keyhole clipping of aneurysm involving branches. (A) Multilobulated wide necked aneurysm at right middle cerebral artery bifurcation incorporating parts of the branches. (B) Elective temporary clipping before dissection of the neck. (C) Postclipping status. (D) Angiographic confirmation of clipping.

the patients. None of the patients in the keyhole group had any retraction changes in MRI at 3 months.
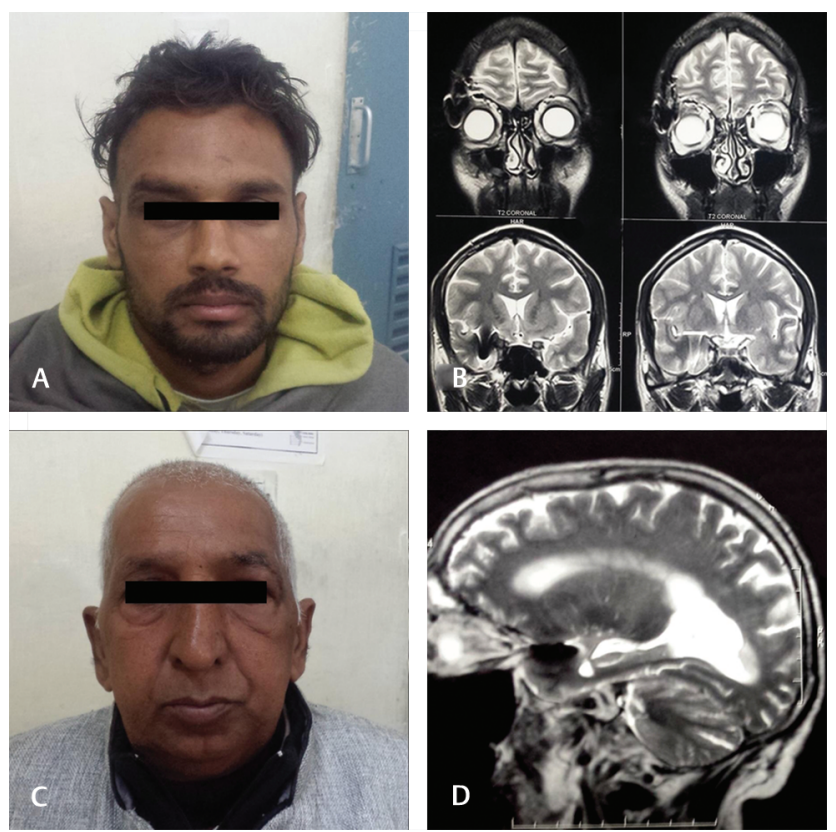

Fig. 4 Minimal operative footprint after keyhole clipping. Good cosmesis ( $A$ and $\mathbf{C}$ ) and lack of retraction changes ( $B$ and $\mathbf{D}$ ) in magnetic resonance imaging after keyhole clipping.

\section{Discussion}

The concept of the supraorbital approach dates back to 1982 when Jane et al described their technique using a bicoronal skin flap for various pathology, including aneurysms. ${ }^{7}$ Further refinement of the techniques was reported in the late 1980s with advances in microscopes and endoscopes. Van Lindert et al described the eyebrow supraorbital keyhole approach for the first time, in their series of unruptured anterior circulation aneurysms without major complications in 1998. ${ }^{5}$ The supraorbital keyhole approach was further expanded and popularized by Perneczky and Fries. ${ }^{8}$ Most of the reports then focused on the feasibility, safety, and outcome of the supraorbital keyhole approach, initially for unruptured aneurysms and subsequently for ruptured aneurysms and other pathologies. ${ }^{9-14}$ Most of these noted good cosmetic satisfaction, pain, and function compared with standard craniotomy. ${ }^{10,11,15,16}$

The present literature on ruptured aneurysms is heterogeneously ambiguous, with only retrospective cohort studies comparing supraorbital keyhole with the pterional approach. Paladino et al, in 2005, compared the results of the keyhole with standard craniotomy done by two groups and documented similar overall surgical outcomes. ${ }^{17}$ Fischer et al, in 2011, compared different types of keyhole with pterional approach and reported comparable outcome. ${ }^{18}$ While some comparative studies $^{19-21}$ have shown shorter operative time, better cosmetic outcome, less blood loss, lower craniotomy complications with keyhole approach, few studies ${ }^{22,23}$ have cautioned on higher procedural complications and intraoperative rupture with keyhole among ruptured aneurysms. In a curious comparison of the keyhole and pterional approaches on opposite sides in the same set of patients, Park et al noted better cosmesis and satisfaction scores on the side of the keyhole but without any details 
Table 1 Comparison between pterional and keyhole clipping

\begin{tabular}{|c|c|c|c|}
\hline & & Pterional & Keyhole \\
\hline \multirow[t]{4}{*}{ Aneurysm location } & Acom & 9 & 8 \\
\hline & MCA & 8 & 8 \\
\hline & ICA & 5 & 5 \\
\hline & Multiple aneurysms & 3 & 4 \\
\hline \multirow[t]{6}{*}{ Intraoperative events } & Dural tear & 4 & 2 \\
\hline & Peri-op CSF drainage & 4 (1 failed) & 22 (3 failed) \\
\hline & Difficult Sylvian fissure & 3 & 4 \\
\hline & Parent vessel exposure & 25 & 25 \\
\hline & Temporary clipping & 20 & 25 \\
\hline & Intra-op rupture & 6 & 7 \\
\hline \multicolumn{2}{|c|}{ Immediate postoperative deficits } & 0 & 0 \\
\hline \multirow[t]{2}{*}{ Delayed cerebral ischemia } & Reversible & 4 & 3 \\
\hline & Irreversible & 2 & 1 \\
\hline \multicolumn{2}{|c|}{ Wound complaints/infection } & 2 & 0 \\
\hline \multirow[t]{2}{*}{ Temporal hollowing ${ }^{\mathrm{a}}$} & Mild & 6 & 1 \\
\hline & Moderate-severe & 3 & 0 \\
\hline \multicolumn{2}{|c|}{ Chewing difficulty } & 7 & 0 \\
\hline
\end{tabular}

Abbreviations: Acom, anterior communicating; CSF, cerebrospinal fluid; ICA, internal carotid artery; Intra-op, intraoperative; MCA, middle cerebral artery; Peri-op, perioperative.

aSignificant $(p<0.05)$.

on procedural complications. ${ }^{24}$ Some other studies comparing pterional keyhole with standard pterional also found comparable outcomes among ruptured aneurysms. ${ }^{25,26}$ All these studies had reported comparisons of outcomes between different surgeons which can be fallacious due to the different levels of expertise and learning curve.

The very few publications comparing keyhole with pterional craniotomy done by the same surgeon had two issues of potential bias. ${ }^{19,27}$ First, they might have probably overestimated the benefits of keyhole performed in the later part of the surgeon's learning curve. Second, it was unclear whether all consecutive cases underwent the keyhole approach or the approach was selected based on morphology, the multiplicity of aneurysms, orientation, anatomical variations, ${ }^{28}$ and sizes of the frontal sinus. The present study is unique, being a single-surgeon study at the time of transition from the pterional to the keyhole approach. Inclusion of all consecutive cases (including multiple aneurysms) as per the criteria and small sample size was intended to evade the biases of patient selection and increasing expertise. This is especially relevant in the surgical approach in the acute setting with a tight brain.

\section{Strengths and Limitations}

Despite the known limitations of keyhole approach, such as difficulty in maneuvering instruments, restricted operative corridor, narrow working angles and the need for coaxial microinstruments, ${ }^{9,19}$ it appears in our study to be safe and effective even in the hands of keyhole beginners with better cosmesis and chewing among the keyhole group. The exclusion of patients in poor grades, those with mass effect, and giant aneurysms, makes our study homogeneous for clinical application. ${ }^{20,29}$ The extensive exposure of the brain in the pterional approach is associated with much of inflammatory markers and underreported cognitive sequelae which also need comparative evaluation. ${ }^{30-33}$ Though a randomized controlled trial comparing the approaches would be the most ideal, the ethical dilemma of not providing the optimal approach as per the expertise may not permit the same. A two-pronged research strategy is needed in future to improve the outcome of aneurysms, both on basic sciences as well as on technical innovations. . $^{34,35}$

\section{Conclusion}

A surgeon experienced in pterional craniotomy can comfortably shift to supraorbital keyhole approach for early clipping of ruptured aneurysms less than $25 \mathrm{~mm}$ in commICA, Acom, and MCA among WFNS grades 1 to 3 with no midline shift, maintaining comparable surgical outcome but better cosmesis and temporalis function.

\section{Funding}

None.

\section{Conflict of Interest}

None declared.

\section{References}

1 Dhandapani S, Singh A, Singla N, et al. Has outcome of subarachnoid hemorrhage changed with improvements in neurosurgical services? Stroke 2018;49(12):2890-2895 
2 Mahak C, Shashi, Yashomati, et al. Assessment of utilization of rehabilitation services among stroke survivors. J Neurosci Rural Pract 2018;9(4):461-467

3 Dhandapani S, Kapoor A, Gaudihalli S, Dhandapani M, Mukherjee KK, Gupta SK. Study of trends in anthropometric nutritional indices and the impact of adiposity among patients of subarachnoid hemorrhage. Neurol India 2015;63(4):531-536

4 Dhandapani S, Aggarwal A, Srinivasan A, et al. Serum lipid profile spectrum and delayed cerebral ischemia following subarachnoid hemorrhage: Is there a relation? Surg Neurol Int 2015;6(suppl 21) :S543-S548

5 van Lindert E, Perneczky A, Fries G, Pierangeli E. The supraorbital keyhole approach to supratentorial aneurysms: concept and technique. Surg Neurol 1998;49(5):481-489, discussion 489-490

6 Vergouwen MD, Vermeulen M, van Gijn J, et al. Definition of delayed cerebral ischemia after aneurysmal subarachnoid hemorrhage as an outcome event in clinical trials and observational studies: proposal of a multidisciplinary research group. Stroke 2010;41(10):2391-2395

7 Jane JA, Park TS, Pobereskin LH, Winn HR, Butler AB. The supraorbital approach: technical note. Neurosurgery 1982;11(4):537-542

8 Perneczky A, Fries G. Endoscope-assisted brain surgery: part 1-evolution, basic concept, and current technique. Neurosurgery 1998;42(2):219-224, discussion 224-225

9 Shin D, Park J. Unruptured supraclinoid internal carotid artery aneurysm surgery: Superciliary keyhole approach versus pterional approach. J Korean Neurosurg Soc 2012;52(4):306-311

10 Reisch R, Marcus HJ, Hugelshofer M, Koechlin NO, Stadie A, Kockro RA. Patients' cosmetic satisfaction, pain, and functional outcomes after supraorbital craniotomy through an eyebrow incision. J Neurosurg 2014;121(3):730-734

11 La Rocca G, Della Pepa GM, Sturiale CL, et al. Lateral supraorbital versus pterional approach: analysis of surgical, functional, and patient-oriented outcomes. World Neurosurg 2018;119:e192-e199

12 Cha KC, Hong SC, Kim JS. Comparison between lateral supraorbital approach and pterional approach in the surgical treatment of unruptured intracranial aneurysms. J Korean Neurosurg Soc 2012;51(6):334-337

13 Singh H, Essayed WI, Jada A, et al. Contralateral supraorbital keyhole approach to medial optic nerve lesions: an anatomoclinical study. J Neurosurg 2017;126(3):940-944

14 Dhandapani S, Sahoo SK. Median supraorbital keyhole approach for clipping ruptured distal anterior cerebral artery aneurysm: Technical report with review of literature. World Neurosurg 2018;112:73-76

15 Zumofen DW, Rychen J, Roethlisberger M, et al. A review of the literature on the transciliary supraorbital keyhole approach. World Neurosurg 2017;98:614-624

16 Dhandapani M, Dhandapani S, Agarwal M, Mahapatra AK. Pain perception following different neurosurgical procedures: a quantitative prospective study. Contemp Nurse 2016;52(4):477-485

17 Paladino J, Mrak G, Miklić P, Jednacak H, Mihaljević D. The keyhole concept in aneurysm surgery-a comparative study: keyhole versus standard craniotomy. Minim Invasive Neurosurg 2005;48(5):251-258

18 Fischer G, Stadie A, Reisch R, et al. The keyhole concept in aneurysm surgery: results of the past 20 years. Neurosurgery 2011;68(1(suppl operative) :45-51, discussion 51
19 Yu L-B, Huang Z, Ren Z-G, et al. Supraorbital keyhole versus pterional craniotomies for ruptured anterior communicating artery aneurysms: a propensity score-matched analysis. Neurosurg Rev 2018;43(2):547-554

20 Genesan P, Haspani MS, Noor SRM. A comparative study between supraorbital keyhole and pterional approaches on anterior circulation aneurysms. Malays J Med Sci 2018;25(5):59-67

21 Xin WQ, Wang WH, Yin Q, Bachelor QX, Cai SF, Yang XY. Meta-analysis of pterional versus supraorbital keyhole approach for clipping intracranial aneurysms: Direct comparison of approach-related complications. World Neurosurg 2019

22 Chalouhi N, Jabbour P, Ibrahim I, et al. Surgical treatment of ruptured anterior circulation aneurysms: comparison of pterional and supraorbital keyhole approaches. Neurosurgery 2013;72(3):437-441, discussion 441-442

23 Madhugiri VS, Ambekar S, Pandey P, et al. The pterional and suprabrow approaches for aneurysm surgery: a systematic review of intraoperative rupture rates in 9488 aneurysms. World Neurosurg 2013;80(6):836-844

24 Park J, Son W, Kwak Y, Ohk B. Pterional versus superciliary keyhole approach: direct comparison of approach-related complaints and satisfaction in the same patient. J Neurosurg 2018;130(1):220-226

25 Yamahata H, Tokimura H, Tajitsu K, et al. Efficacy and safety of the pterional keyhole approach for the treatment of anterior circulation aneurysms. Neurosurg Rev 2014;37(4):629-636

26 Tang Y, Chen H, Ma F, et al. Experience using the pterional keyhole approach for the treatment of ruptured intracranial aneurysms of the anterior circulation. World Neurosurg 2018;118:e800-e805

27 Park HS, Park SK, Han YM. Microsurgical experience with supraorbital keyhole operations on anterior circulation aneurysms. J Korean Neurosurg Soc 2009;46(2):103-108

28 Singh H, Dhandapani S, Mathuriya SN. Types of azygos distal anterior cerebral artery branching patterns: relevance in aneurysmal surgery. Cureus 2016;8(7):e681

29 Park JS, Kim H, Baik MW, Park IS. Risk factor analysis for poor outcomes in supraorbital keyhole aneurysm clipping for ruptured anterior circulation aneurysms. World Neurosurg 2018;111:e386-e394

30 Mohanty M, Dhandapani S, Gupta SK, et al. Cognitive impairments after clipping of ruptured anterior circulation aneurysms. World Neurosurg 2018;117:e430-e437

31 Kumar M, Goudihalli S, Mukherjee K, Dhandapani S, Sandhir R. Methylenetetrahydrofolate reductase C677T variant and hyperhomocysteinemia in subarachnoid hemorrhage patients from India. Metab Brain Dis 2018;33(5):1617-1624

32 Kapoor A, Dhandapani S, Gaudihalli S, Dhandapani M, Singh H, Mukherjee KK. Serum albumin level in spontaneous subarachnoid haemorrhage: more than a mere nutritional marker! $\mathrm{Br}$ J Neurosurg 2018;32(1):47-52

33 Balasubramanian M, Kuberan A, Rawat A, et al. Effect of general anesthetics on caspase-3 levels in patients with aneurysmal subarachnoid hemorrhage: a preliminary study. J Neurosurg Anesthesiol 2021;33(2):172-6

34. Dhandapani S, Wankhede LS. Orbital rim sparing single-piece fronto-orbital keyhole craniotomy through eyebrow incision: A technical report and comparative review. Neurol India 2021;69(2):441-445

35. Sharma T, Datta KK, Kumar M, et al. Intracranial Aneurysm Biomarker Candidates Identified by a Proteome-Wide Study. OMICS 2020;24(8):483-492 